\title{
The evaluation of $\mathrm{CO}_{2}$-based vapour extraction (VAPEX) process for heavy-oil recovery
}

\author{
Farshid Torabi • Benyamin Yadali Jamaloei • \\ Blair M. Stengler • Drew E. Jackson
}

Received: 19 March 2012/Accepted: 14 May 2012/Published online: 10 July 2012

(C) The Author(s) 2012. This article is published with open access at Springerlink.com

\begin{abstract}
Vapor extraction (VAPEX) has been proposed as an alternative for heavy-oil recovery in reservoirs where thermal methods face technical and economic problems. In VAPEX, a pair of horizontal injector-producer wells is employed. The gaseous hydrocarbon solvent (normally propane or a mixture of methane-propane or propanebutane) is injected from the top well and the diluted oil drains downward by gravity to the bottom producer. Recently, the idea of incorporation of $\mathrm{CO}_{2}$ into the gaseous hydrocarbon mixture has emerged. Incorporation of $\mathrm{CO}_{2}$ is believed to make the process more economical and environmentally and technically attractive. $\mathrm{CO}_{2}$ is cheaper than the hydrocarbon gases and has higher solubility into the heavy oil than most of the hydrocarbon gases. It also adds value to the environmental side of the process as $\mathrm{CO}_{2}$ can be sequestered while improving the VAPEX performance at the same time. Moreover, the addition of $\mathrm{CO}_{2}$ to the injected gas increases the dew point of the solvent mixture, and solvent mixtures with higher dew point can be used in heavy-oil reservoirs with higher pressure in which the mixture of hydrocarbon gases may partly condense, which decreases the VAPEX efficacy. Thus, the advantage of incorporating $\mathrm{CO}_{2}$ into the injected solvent is threefold. The objective of this work, therefore, is to simulate the
\end{abstract}

F. Torabi $(\bowtie) \cdot$ B. Yadali Jamaloei · B. M. Stengler ·

D. E. Jackson

Petroleum Systems Engineering Department,

Faculty of Engineering and Applied Science,

The University of Regina, Regina, SK, Canada

e-mail: farshid.torabi@uregina.ca

Present Address:

B. Yadali Jamaloei

The Department of Chemical and Petroleum Engineering, The Schulich School of Engineering, The University of Calgary, Calgary, AB T2N 1N4, Canada performance of the VAPEX process when different solvent mixtures, including hydrocarbon gases and $\mathrm{CO}_{2}$, are incorporated with the aim of improving its performance. The design and the major results of the simulation for the $\mathrm{CO}_{2}$-based VAPEX process are discussed.

Keywords Vapour extraction (VAPEX) $\cdot \mathrm{CO}_{2}$. Simulation · Performance evaluation · Heavy-oil recovery

\section{Introduction}

Bitumen and heavy-oil recovery issues

The worldwide bitumen and heavy-oil reserves are estimated at over 6 trillion barrels, a substantial portion of which resides in Western Canada (Upreti et al. 2007). The high viscosity of heavy oil renders conventional production methods ineffective, if not impossible (Farouq Ali 1974). Steam-assisted gravity drainage (SAGD) has proven to be an effective practice for increasing recovery from heavy-oil reservoirs (Butler 1991). In reservoirs with thin pay zones, bottom aquifers, and high water saturation, and in shaly formations, SAGD faces numerous problems. As such, there is a strong demand for alternative techniques that can provide a similar increase in production from such heavyoil reservoirs.

These alternative methods include VAPEX (Butler and Mokrys 1991), toe-to-heel in situ combustion (Xia et al. 2003), toe-to-heel steam flooding (Turta et al. 2008), toeto-heel waterflooding (Turta and Singhal 2004), surfactantbased chemical flooding in the presence and absence of polymer and alkali (Liu et al. 2006; Mai et al. 2009; Thomas et al. 2001; Yadali Jamaloei et al. 2010a, b; Yadali Jamaloei and Kharrat 2010), low-rate waterflooding 
(Mai and Kantzas 2010), variable-rate waterflooding (Torabi et al. 2012), immiscible $\mathrm{CO}_{2}$ flood (Spivak and Chima 1984; Torabi et al. 2012), and water-alternating$\mathrm{CO}_{2}$ injection (Farouq Ali 1976; Rojas et al. 1991; Thomas et al. 2001; Torabi et al. 2012). Among these methods, VAPEX has gained considerable attention (Das and Butler 1998; Upreti et al. 2007). For a detailed review of VAPEX, we refer the interested reader to Upreti et al. (2007). Meanwhile, we solely provide a brief background on the essential features of VAPEX and its solvent-related issues to demonstrate why solvent mixtures including $\mathrm{CO}_{2}$ are believed to have the potential to improve VAPEX performance.

Technical background: essential features of the VAPEX process

Vapour extraction and SAGD share a common objective of decreasing the viscosity of the heavy oil and allowing it to drain by gravity. Both SAGD and VAPEX involve a horizontal injection well directly above a horizontal production well. In VAPEX, however, a vaporized hydrocarbon solvent is injected in place of steam as is used in SAGD. In VAPEX, solvent dissolves into the oil near the injection wellbore, diluting the oil and decreasing its viscosity. Once this diluted oil breaks through to the producing well, the injected solvent rises and begins to form a vapour chamber (Das and Butler 1998). The two basic processes involved in VAPEX are mass transfer of the solvent into the oil and gravity drainage of the diluted oil to the production well. At first, the transfer of solvent molecules into the oil occurs primarily through molecular diffusion. Once the communication is established between the two wells, the injected solvent begins to rise and forms a vapour chamber. The chamber will continue to rise until it reaches the cap rock. At this point, the chamber begins to spread laterally (Butler and Mokrys 1991). Field-scale application of VAPEX remains very limited. No commercial-scale VAPEX projects exist to date. Several pilot projects are currently operating. Nexen Inc., Imperial Oil, Encana, Petro-Canada, and Baytex Energy Ltd. have been operating pilot projects as of 2007.

There are several features associated with the VAPEX process which make it attractive to the petroleum industry. First, VAPEX is carried out at reservoir temperature, and therefore, the heat loss does not occur. The energy requirements of a VAPEX project are estimated to be approximately $3 \%$ of those for a SAGD project (Upreti et al. 2007). Second, some portion of the injected solvent can be recovered with the use of typical separation facilities (Butler et al. 1995). In addition, the initial capital expenditure for a VAPEX process can be substantially less than a thermal project. Third, VAPEX boasts several benefits over thermal processes on the environmental side. During a pressure blowdown for solvent recovery, a gas must be injected to occupy the void left by the recovered solvent. A greenhouse gas such as $\mathrm{CO}_{2}$ can be used for this purpose. This allows for the geological storage of significant amounts of $\mathrm{CO}_{2}$ (Luhning et al. 2003). $\mathrm{CO}_{2}$ can also be included as a part of the solvent. Finally, one of the most attractive features of VAPEX is the in situ upgrading of the oil, which occurs through asphaltene precipitation, or deasphalting. The viscosity of the oil is drastically reduced by the removal of these components (Luo and Gu 2005; Luo et al. 2007).

Three variants of VAPEX have been proposed (James et al. 2007), namely: (1) conventional, (2) warm, and (3) hybrid. In conventional VAPEX, the effectiveness of the process relies solely on the mass transfer of solvent into the oil. In warm VAPEX, the solvent is heated before being injected into the reservoir whereby faster reduction in viscosity of the oil causes an earlier establishment of the communication between the wells (James et al. 2007). In hybrid VAPEX, steam and solvent are co-injected where the steam requirements can be drastically reduced as compared to the conventional SAGD, and the solvent recovery is greater than that of conventional VAPEX (Butler and Mokrys 1991).

\section{Solvent-related issues in VAPEX}

The majority of VAPEX studies utilize propane as the injected solvent. Propane is one of the least-expensive hydrocarbon solvents available and is able to provide satisfactory solubility into heavy oil. However, pure propane cannot be used as a solvent in VAPEX, in most cases in which its vapour pressure is well below the heavy-oil reservoir pressure. If propane alone is injected, it would be in the liquid state and the process would be less effective (Badamchi-Zadeh et al. 2008). A vaporized solvent provides a greater gravity differential than a liquid, and the diffusion of a gas into oil will generally occur much faster than with a liquid solvent. For the solvent to be in the vapour state at reservoir conditions, a non-condensable gas must be added to the propane.

\section{Problem statement}

The search for the ideal non-condensable gas to be added to the solvent is on going. When a non-condensable gas such as methane is blended with propane, dew point pressures of the mixture increase significantly. The basic solvent mixtures usually consist of propane as a base blended with methane, ethane, butane, nitrogen, or $\mathrm{CO}_{2}$. At first, many considered the addition of methane in various weights to a propane-based solvent. Hydrocarbon gases such as 
methane and propane are very expensive, and the feasibility of the VAPEX process depends largely on the solvent cost. Recently, $\mathrm{CO}_{2}$ has become a topic of interest in this area for several reasons (Badamchi-Zadeh et al. 2009). $\mathrm{CO}_{2}$ is more soluble in heavy oil than the propane, and it, therefore, generates a more significant reduction in oil viscosity (Talbi and Maini 2004). In many cases, $\mathrm{CO}_{2}$ is released to the atmosphere as a process bi-product in the form of a flue or exhaust gas. The extraction and transportation of such flue gases has been proven to be possible and economical in the past. Ultimately, the incorporation of $\mathrm{CO}_{2}$ in the solvent injected during the VAPEX process would yield two main advantages. First, it would decrease the cost of the injected solvent. Second, the opportunity exists to effectively sequester $\mathrm{CO}_{2}$ and thereby to reduce greenhouse gas content in the atmosphere. It is, therefore, the main objective of this paper is to simulate the performance of VAPEX when different solvent mixtures, including $\mathrm{CO}_{2}$ gas, are incorporated with the aim of improving its performance.

A compositional simulator is necessary since the effectiveness of $\mathrm{CO}_{2}$-based VAPEX depends entirely on the ability of the injected solvent to modify the composition of the oil. The complexities commonly encountered in Canadian heavy-oil reservoirs such as geological heterogeneities, fractures, wormholes, faults, and permeability variation tend to complicate the analysis of $\mathrm{CO}_{2}$-based VAPEX. The main objective of this study is to investigate the effect of modifying the solvent composition on the effectiveness of $\mathrm{CO}_{2}$-based VAPEX process. Therefore, to avoid all the complexities commonly encountered in Canadian heavy-oil reservoirs, a homogeneous reservoir model was designed in an attempt to solely focus on the effect of modifying solvent composition. In addition, selection of such a homogeneous model reduced the simulation run time without compromising the results. Hence, in this study, the changes that might occur in the performance of different cases obtained from the simulation are merely attributed to the different solvent composition. The reservoir properties were selected so as to represent a typical heavy-oil reservoir in Western Canada. The collected data were not taken from any one specific reservoir. Instead, properties from multiple locations were incorporated into the simulation model to create a representative reservoir with average properties.

\section{Simulation design}

Reservoir model

Computer Modelling Group's (CMG) GEM module is used in this work to study the performance of the $\mathrm{CO}_{2}$-based VAPEX process. To model a horizontal well pair, a rectangular reservoir with Cartesian grids was used. The well lengths in the VAPEX process can range anywhere from 700 to $1,000 \mathrm{~m}$. The upper limit of $1,000 \mathrm{~m}$ was used for the model in this study. A width of $130 \mathrm{~m}$ was selected to include in the drainage area of a well pair during VAPEX operations in the model. As demonstrated in "General results of simulation: predicting essential features of the VAPEX process", as a result of including LGR in the vertical cross-section, the vapour chamber in the simulation is well developed with relatively smooth edges and the expected shape, according to the original theory. This shows that the essential features of the VAPEX process can be captured utilizing the simulation model designed in this study. It also shows that the designed model reasonably represents the features of a real reservoir. Table 1 summarizes the reservoir properties allocated to the simulation model. The porosity and permeability values chosen here are quite close to those of some reservoir rocks in Western Canada (especially in Saskatchewan), Hamaca and Cerro Negro Fields in Venezuela, Draugen Field in Norway, etc. Figure 1 is a three-dimensional representation of the reservoir model showing the refined grid definition in the vertical cross-section. Once the reservoir model was built and the array properties were assigned for each layer, the fluid model was imported to the GEM module from CMG's WinProp module. The relative permeability data as shown in Figs. 2 and 3 were determined using available

Table 1 Reservoir properties used for simulation

\begin{tabular}{ll}
\hline Porosity $(\%)$ & 30 \\
Permiability I,J,K (mD) & 4000 \\
Temperature $\left({ }^{\circ} \mathrm{C}\right)$ & 22 \\
Initial Pressure $(\mathrm{kPa})$ & 3700 \\
Length (m) & 1000 \\
Height (m) & 10 \\
Width (m) & 130 \\
Initial Oil Saturation & 0.82 \\
\hline
\end{tabular}

Permeability I, J, K illustrates the permeability value in $\mathrm{X}, \mathrm{Y}, \mathrm{Z}$ directions respectively
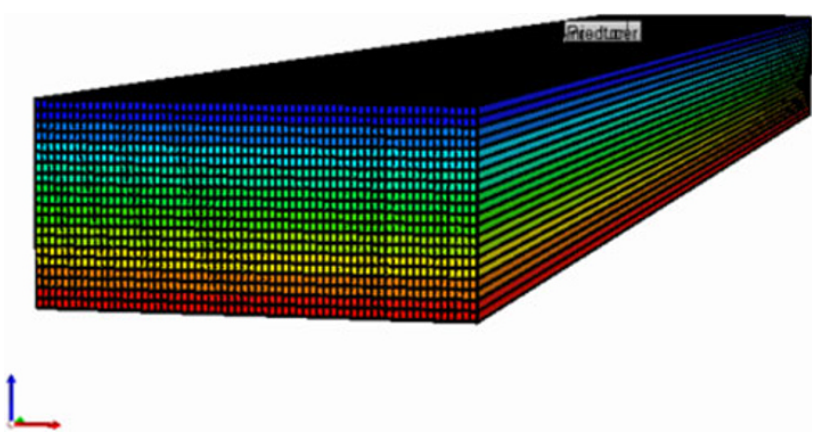

Fig. 1 Three-dimensional representation of the reservoir model showing LGR in the vertical cross-section 


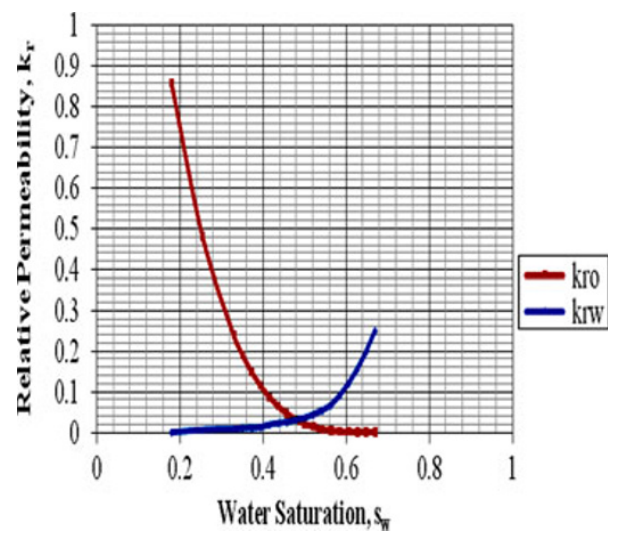

Fig. 2 Oil-water relative permeability curves

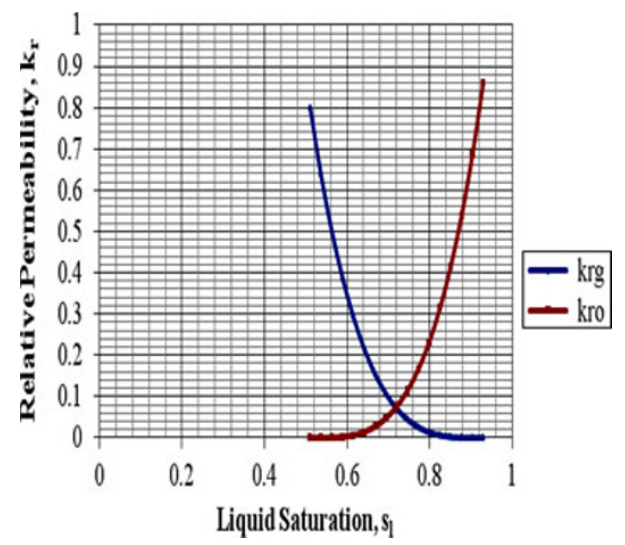

Fig. 3 Oil-gas relative permeability curves

correlations in $\mathrm{CMG}$ for unconsolidated sandstone. The initial pressure of $3,700 \mathrm{kPa}$ at the top of the reservoir and a uniform temperature of $22{ }^{\circ} \mathrm{C}$ were used.

Fluid model

The CMG WinProp module was used to generate an equation of state fluid model. This fluid model was then imported into the CMG compositional simulator, GEM. In summary, in the WinProp module, first, the experimental physical data for the heavy oil were introduced. Then, regression analysis was conducted to match the data and tune the equation of state. Using multiple regressions on the various available data, we tuned the equation of state model to accurately represent the phase behavior of the heavy-oil sample used in this simulation study. The detailed procedure is explained as follows. The physical properties for the two dead oil samples used in this study are given in Table 2. The live oil sample $\mathrm{A}$ at a saturation pressure of $3440 \mathrm{kPa}$ contains $0.02 \% \mathrm{~N}_{2}, 12.93 \% \mathrm{C}_{1}$, $0.01 \% \mathrm{C}_{2}, 0.01 \% \mathrm{C}_{3}$, and $87.03 \% \mathrm{C}_{6+}$ fraction. The live oil sample $\mathrm{B}$ at a saturation pressure of $3420 \mathrm{kPa}$ contains
$0.02 \% \mathrm{~N}_{2}, 14.80 \% \mathrm{C}_{1}$, and $85.18 \% \mathrm{C}_{6+}$ fraction. The Modified Pedersen Corresponding States Model was selected for viscosity calculations. The live oil composition was then used for the heavy oil at its saturation pressure at temperature of $31^{\circ} \mathrm{C}$.

The first required regression is to correct the saturation pressure estimate. The regression analysis was repeated, updating the component properties after each run, until a calculated saturation pressure within $1.0 \%$ difference of our experimental data was achieved. Afterwards, the regression analysis was performed to match the experimental values for dead oil density. After running the regression for several times and updating the component properties following each run, the calculated results matched the experimental density values with an error of $<1.0 \%$. The last regression performed was to match the experimental values for viscosity. The weight for viscosity in all forms was set to one. Once the regression process was repeated for several times, the calculated viscosity values within $10.0 \%$ error of the experimental data were determined. The regression results and the experimental values for density and viscosity for oil samples $\mathrm{A}$ and $\mathrm{B}$ are summarized in Table 2. Once the equation of state model had been tuned to accurately predict saturation pressure, single phase calculations were performed for pressures ranging from 1,000 to $10,000 \mathrm{kPa}$ at intervals of $1,000 \mathrm{kPa}$. Finally, a two-phase flash calculation was conducted at the reservoir pressure and temperature to obtain the initial oil composition at reservoir conditions. This tuned fluid model was then imported to the GEM module for conducting simulations.

\section{Solvent analysis}

In general, the compositions consisted of various mole percentages of methane $\left(C_{1}\right)$ and propane $\left(C_{3}\right)$ as the hydrocarbon gaseous solvents and $\mathrm{CO}_{2}$ as the non-condensable gas. Different solvents with different compositions containing $\mathrm{CO}_{2}$ were then compared to the solvents not containing $\mathrm{CO}_{2}$. In this way, we could determine how the addition of $\mathrm{CO}_{2}$ to the solvent affects the overall performance of the $\mathrm{CO}_{2}$ VAPEX process. Examining the twophase envelopes enabled us to determine whether a particular solvent will be in the liquid phase, vapour phase, or a mixture at reservoir conditions. An example of a produced P-T diagram using the WinProp module at reservoir conditions is shown in Fig. 4.

Simulation base case and variables

\section{Base case}

A base case for the simulation was established as a means for comparing the effects of changing various parameters 
Table 2 Measured and simulated physical properties of dead oil samples at $100 \mathrm{kPa}$

\begin{tabular}{|c|c|c|c|c|c|}
\hline \multirow[t]{2}{*}{ Quantity } & \multirow{2}{*}{$\begin{array}{l}\text { Temperature, } \\
{ }^{\circ} \mathrm{C}\end{array}$} & \multicolumn{2}{|l|}{ Oil A } & \multicolumn{2}{|l|}{ Oil B } \\
\hline & & Measured & Calculated & Measured & Calculated \\
\hline \multirow[t]{3}{*}{ Density, $\mathrm{kg} / \mathrm{m}^{3}$} & 15 & 995.1 & 992.8 & 999.2 & 996.2 \\
\hline & 21 & 992.5 & 991.4 & 996.2 & 995.1 \\
\hline & 31 & 985.5 & 988.9 & 989.2 & 993.2 \\
\hline \multirow[t]{3}{*}{ Viscosity, $m \mathrm{~Pa} \bullet \mathrm{s}$} & 15 & 37070 & 37025 & 60970 & 58278 \\
\hline & 21 & 20550 & 18652 & 30510 & 28611 \\
\hline & 31 & 6105 & 6632 & 8870 & 9786 \\
\hline API Gravity & 15 & 10.6 & & 10.0 & \\
\hline \multicolumn{2}{|c|}{ Molecular weight, $\mathrm{g} / \mathrm{mol}$} & 412 & & 461 & \\
\hline \multicolumn{2}{|l|}{ Saturates, wt.\% } & 28.9 & & 34.4 & \\
\hline \multicolumn{2}{|l|}{ Aromatics, wt. $\%$} & 39.5 & & 37.7 & \\
\hline \multicolumn{2}{|l|}{ Resins, wt.\% } & 13.9 & & 11.1 & \\
\hline \multicolumn{2}{|l|}{ Asphaltenes, wt.\% } & 14.7 & & 15.1 & \\
\hline
\end{tabular}

on the performance of the $\mathrm{CO}_{2}$ VAPEX. The reservoir characteristics, reservoir model, and fluid model for the base case are given in "Reservoir model" and "Fluid model". The well configuration modeled is the standard VAPEX setup. The horizontal production well was located $0.5 \mathrm{~m}$ from the bottom of the reservoir. The horizontal injection well was placed directly above the horizontal producer with a vertical well spacing of $3 \mathrm{~m}$. The maximum pressure at the injection well was set at 3,750 $\mathrm{kPa}$. A library of solvents was developed, and the state of each solvent at reservoir conditions was determined. Solvents that are primarily liquid were discarded. Several simulations using solvents containing only propane and methane were run initially. A portion of the methane content was then substituted with $\mathrm{CO}_{2}$. This provided a basis to evaluate the impact of adding $\mathrm{CO}_{2}$ to the solvent. A total of 36 different solvent compositions were used in this study. Each simulation was run for 20 years. A vertical cross-section of the reservoir with the wells included is shown in Fig. 5.

\section{Simulation variables}

Once the base case was established, other parameters could be varied one at a time so as to determine their effect on the performance of $\mathrm{CO}_{2}$ VAPEX. The reservoir rock properties remained constant while parameters of interest varied from one simulation run to another. The parameters of interest include the following.

Solvent composition The solvents primarily considered for use were pure light hydrocarbons such as propane or butane. When solvent is injected in the vapour phase, the solvent migrates through the reservoir and dissolves into the oil. The addition of a non-condensable gas such as methane, nitrogen, or $\mathrm{CO}_{2}$ is recommended so as keep the solvent in the vapour phase. The major benefit of using hydrocarbon gases as the main component of the solvent is the associated increased solubility in oil.

Reservoir temperature The benefit of an increase in temperature is threefold: the initial viscosity of the oil is lower, the solubility of the solvent in oil is greater, and the solvent is less likely to condense. To investigate the impact of temperature on the $\mathrm{CO}_{2}$ VAPEX process, simulations were conducted at three different reservoir temperatures: (1) $17{ }^{\circ} \mathrm{C}$, (2) $22{ }^{\circ} \mathrm{C}$, and (3) $27{ }^{\circ} \mathrm{C}$.

Reservoir pressure If the reservoir pressure is greater than the dew point pressure of any solvent, the solvent becomes susceptible to condensation. As stated earlier in "Base case", the solvents that were identified to be initially in the liquid phase were discarded, as they have detrimental effects on the VAPEX process. The two reservoir pressure cases we have studied are: (1) $3,700 \mathrm{kPa}$ and (2) $5,700 \mathrm{kPa}$.

Vertical wellbore spacing The optimal vertical well spacing between injection and production wells during the VAPEX process should be determined with care. Thus, we decided to vary the vertical well spacing in our simulation model over the range of 3-8 $\mathrm{m}$.

Oil composition To examine how the composition of the oil affects the performance of the $\mathrm{CO}_{2}$ VAPEX process, a second WinProp model was created for a different oil composition. This particular second oil composition

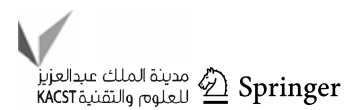




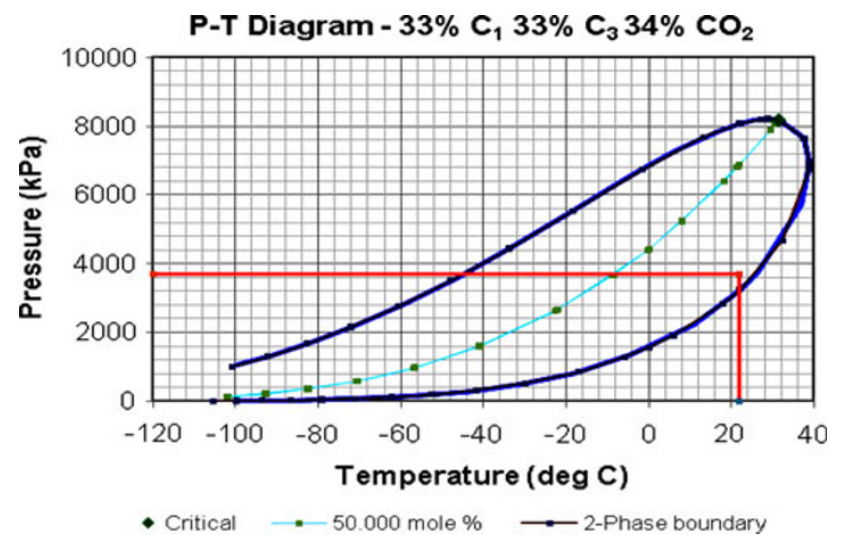

Fig. 4 Example of P-T diagram showing the reservoir conditions for the base case. The point where the vertical and horizontal red lines cross determines the reservoir condition for the base case considered in the simulation model

contained much heavier components with higher viscosity than the first oil.

\section{Simulation results and discussion}

General results of simulation: predicting essential features of the VAPEX process

Cross-sectional views of the reservoir (illustrating oil saturation distribution) at different stages throughout the 20-year simulation time are shown in Figs. 6, 7, 8, 9, and also, the figures show the development and propagation of the solvent vapour chamber, which have been predicted by running the simulation model, during the time of the operation. These four figures indicate that the development and growth of the vapour chamber is predicted accurately (according to the theory of VAPEX mentioned in "Introduction") by the simulation in this study. Moreover, in a full-fledged simulation of VAPEX, the communication between the injection and production wells should be predicted during the early stages. Again, our simulation model has predicted this essential feature of the VAPEX process very accurately (see Fig. 6). The initial date of the simulation is January 1, 2010. The breakthrough of the injected gas to the production well was observed within the first year of operation in the conducted simulation (at the time August 13, 2010 according to Fig. 6). The distribution of the oil saturation throughout the reservoir at this time is depicted in Fig. 6. A significant increase in Gas-oil ratio (GOR) was observed at the production well at this exact time (August 13, 2010). Figure 7 is of particular interest, as it shows the time when the live oil film reached the production well, which has been diluted by the injected solvent. At this time, an increase in oil production was observed (September 1, 2014). Figures 8 and 9 are the snapshots of the reservoir cross-section indicating oil saturation distribution and the development of the solvent chamber after 10 and 20 years, respectively.

\section{Effect of injected solvent composition}

Several simulations were run using injected solvents containing methane and propane only. The propane content ranged from 20 to $80 \%$. These runs established a base case
Fig. 5 Vertical cross-section of the reservoir indicating well locations and initial pressure distribution

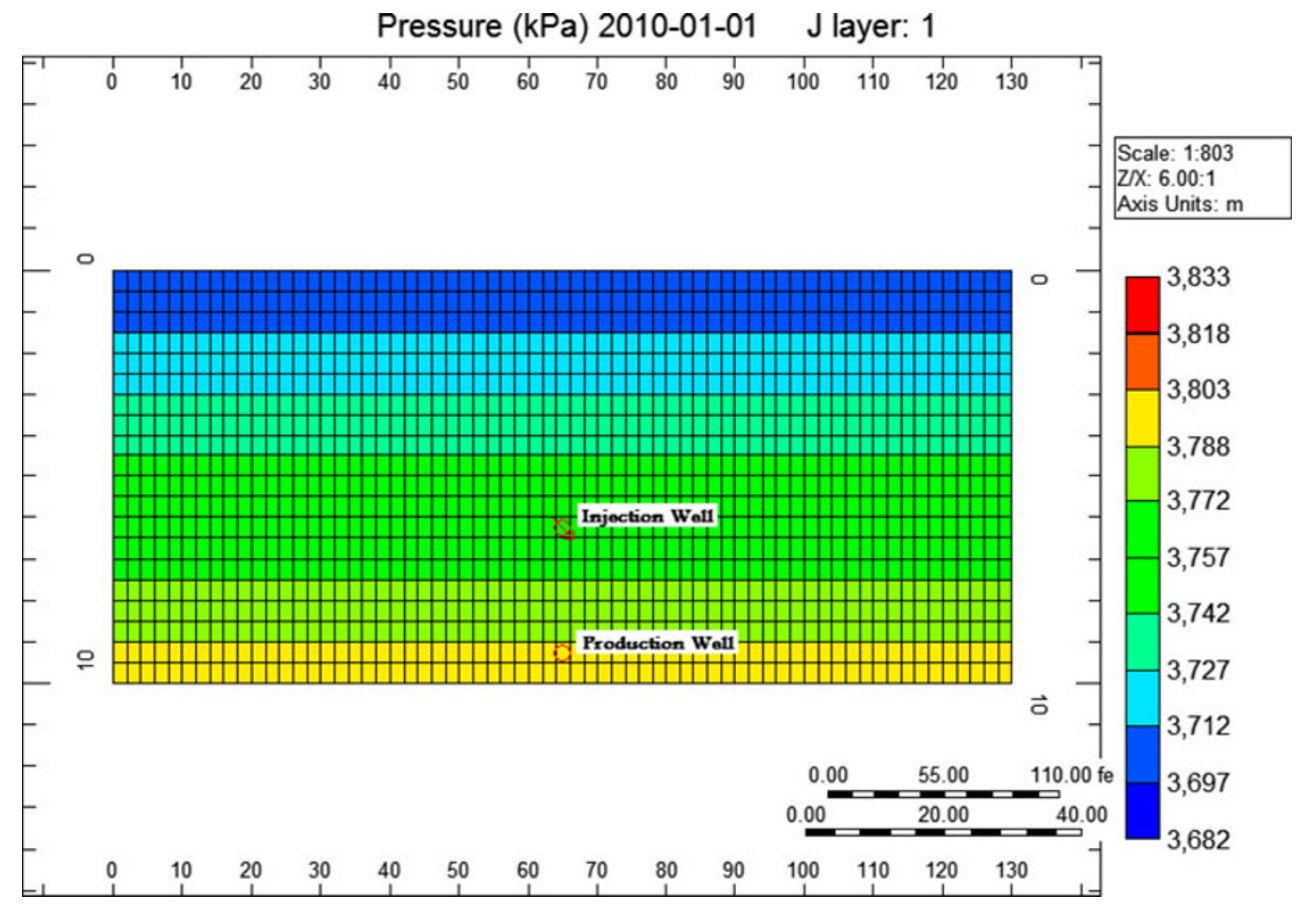


Fig. 6 Demonstration of oil saturation distribution through the model at the early stages (August 13, 2010).

Communication between the wells is established. The injector is at the top and the producer is at the bottom

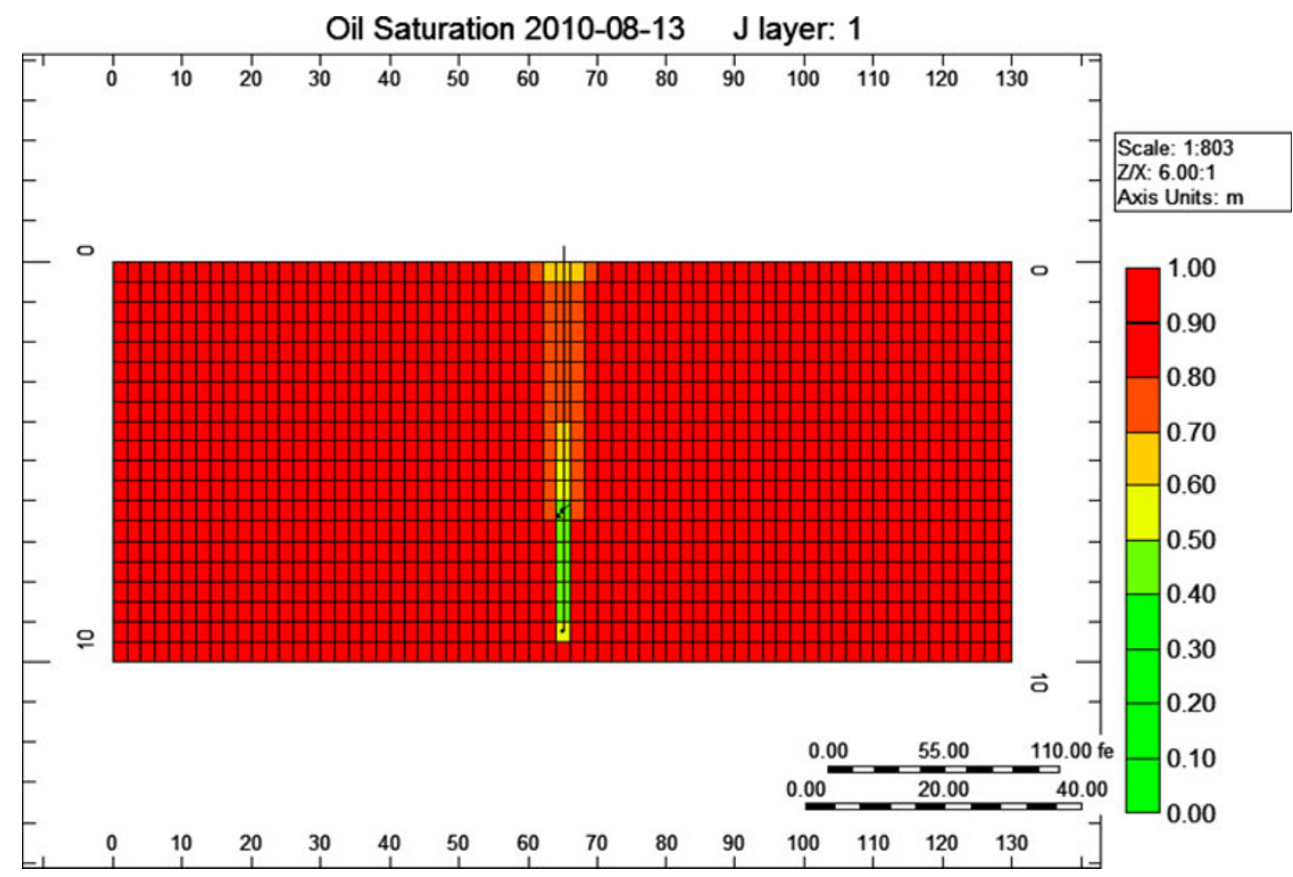

Fig. 7 Live oil film reaches producer at the time September 1,2014 . The oil film is now less viscous as it has been diluted by the solvent. The diluted oil film drains towards the production well due to the existing gravity throughout the model

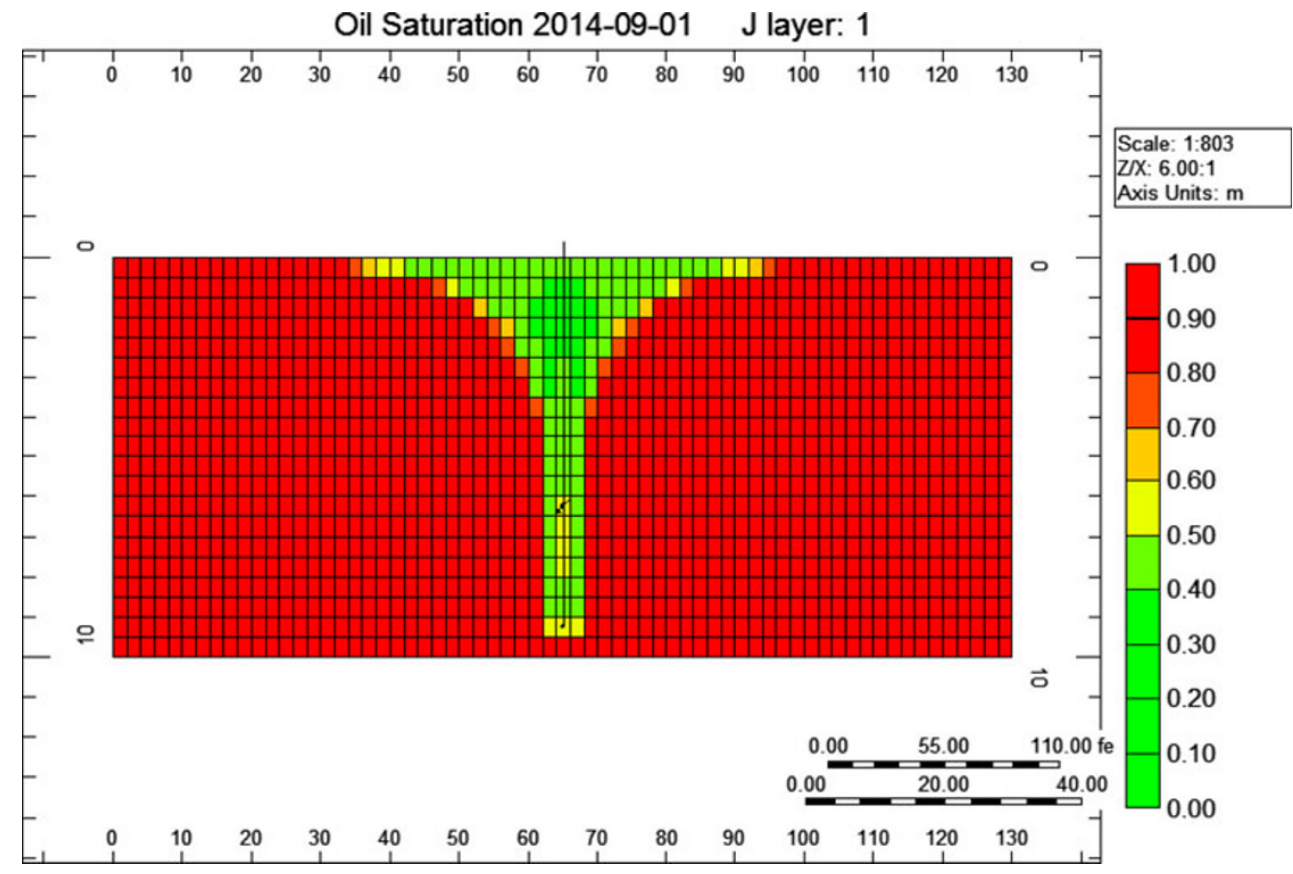

to which the performance of the solvents containing $\mathrm{CO}_{2}$ could be compared. The cumulative production after 10 and 20 years of operation were predicted in simulation. The performance of the methane-propane mixtures is shown in Fig. 10. It appears that an increase in oil-recovery factor is gained by increasing the amount of propane in the solvent within the range of $20-40 \%$ propane $\left(\mathrm{C}_{3}\right)$ content. Beyond $40 \%$ propane content in the injected solvent, no gain in oil-recovery factor was observed. In fact, a slight decrease was even noted after 10 and 20 years of solvent injection when the propane content was increased from 40 to $50 \%$. It is concluded, therefore, that the addition of a non-condensable gas in the range of 30 to 60 molar percent would not have a detrimental effect on the performance of the VAPEX process.

Once the previous simulations were completed, solvents containing $\mathrm{CO}_{2}$ were evaluated. Solvents with equal molar fractions of propane were compared. In a similar fashion as described above, solvents containing $\mathrm{CO}_{2}$ were analyzed by plotting overall oil-recovery factor versus the 
Fig. 8 Shape of the solvent vapour chamber together with the oil distribution throughout the model after 10 years (simulation time: January 1 , 2020)

Fig. 9 Final shape of the solvent vapour chamber together with the oil distribution throughout the model after 20 years (simulation time: January 1, 2030)
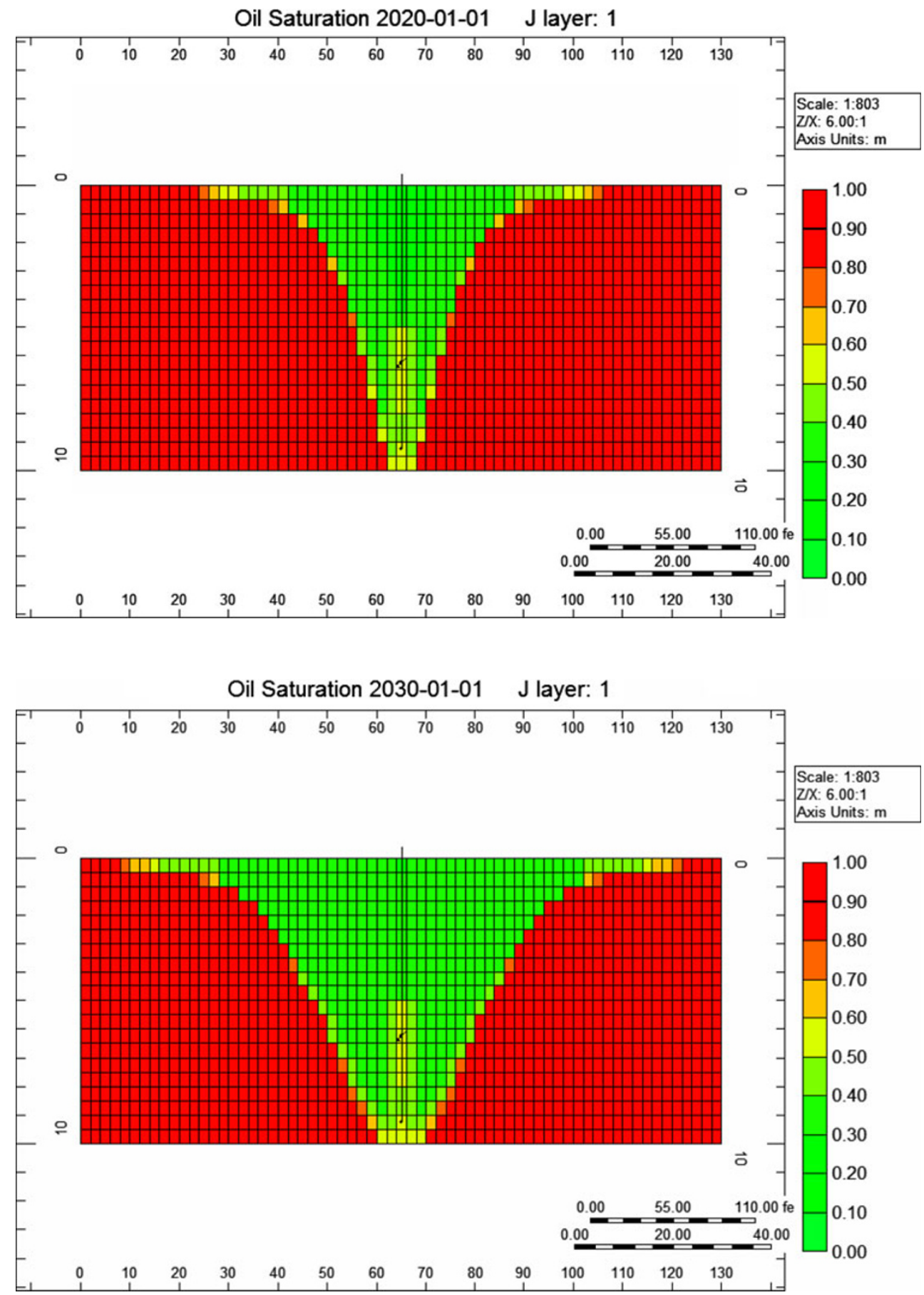

percentage of methane that had been substituted with $\mathrm{CO}_{2}$. The fraction of the methane substitution was calculated as:

Fraction of $\mathrm{C}_{1}$ substitution $=\frac{100-\mathrm{C}_{3} \text { fraction }-\mathrm{C}_{1} \text { fraction }}{100-\mathrm{C}_{3} \text { fraction }}$

This represents the portion of methane $\left(C_{1}\right)$ in the original solvent that is replaced by $\mathrm{CO}_{2}$. In this simulation study, we tested methane substitution fractions ranging from 0 to $100 \%$. Figure 11 shows that the substitution of $\mathrm{CO}_{2}$ did not lead to a decrease in overall oil-recovery factor. In fact, solvents with higher amounts of $\mathrm{CO}_{2}$ performed better than the solvents containing relatively lower amounts of $\mathrm{CO}_{2}$. This was the case for the mixtures containing $20 \%$ propane as shown in Fig. 11. The graphs for oil-recovery factor versus fraction of $\mathrm{C}_{1}$ substitution by $\mathrm{CO}_{2}$ for solvents containing various amounts of propane are given in Figs. 12, 13, 14, 15. The substitution of 


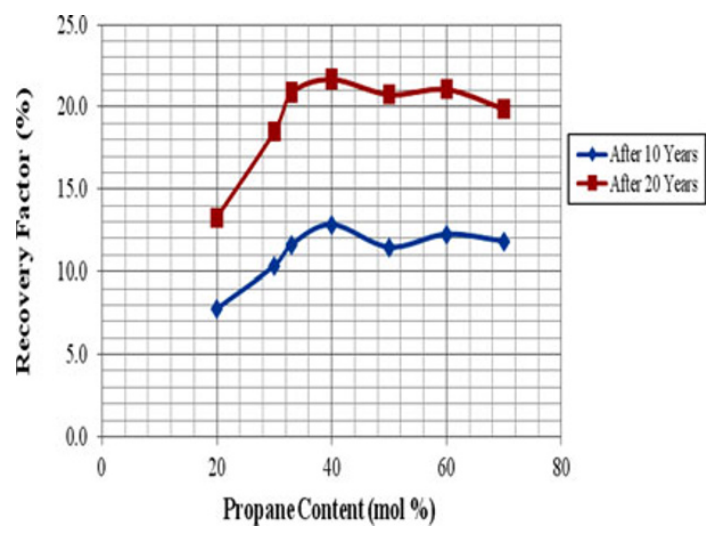

Fig. 10 Recovery versus $C_{3} \%$ for $C_{1}-C_{3}$ mixture

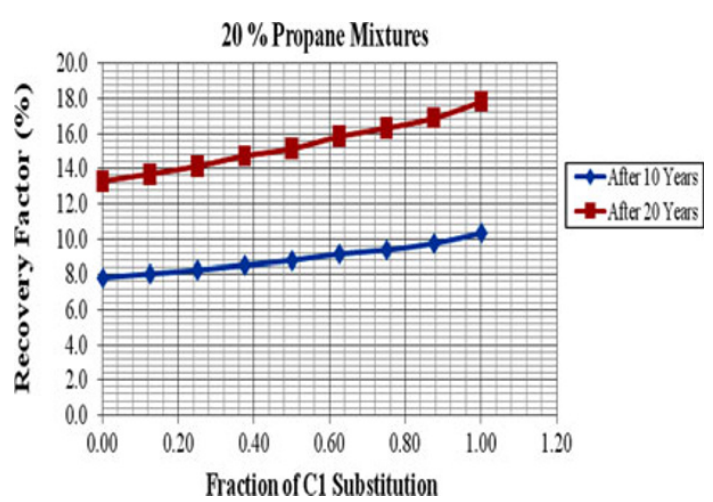

Fig. 11 Recovery versus $\mathrm{CO}_{2} \%$ in $\mathrm{C}_{1}-\mathrm{C}_{3}-\mathrm{CO}_{2}$ mixture

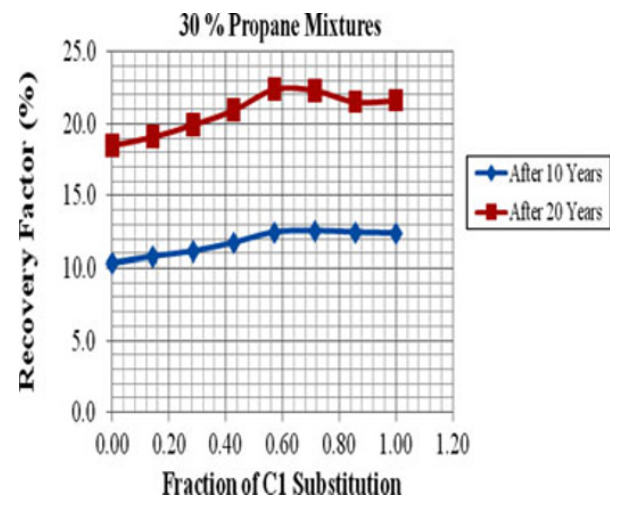

Fig. 12 Recovery versus $\mathrm{CO}_{2} \%$ in $\mathrm{C}_{1}-\mathrm{C}_{3}-\mathrm{CO}_{2}$ mixture

methane with $\mathrm{CO}_{2}$ not only did not negatively impact the VAPEX performance but also generally increased the ultimate oil-recovery factor (i.e., at the end of 20 years of solvent injection) in the range of $0-60 \%$ of $\mathrm{C}_{1}$ substitution by $\mathrm{CO}_{2}$. The increase of $\mathrm{CO}_{2}$ proportion $\left(\mathrm{C}_{1}\right.$ substitution by $\mathrm{CO}_{2}$ ) above the $60 \%$ generally caused a decrease in the ultimate oil-recovery factor after 20 years of solvent injection (see Figs. 11, 12, 13, 14, 15). These findings indicate that the amount of methane gas that should be

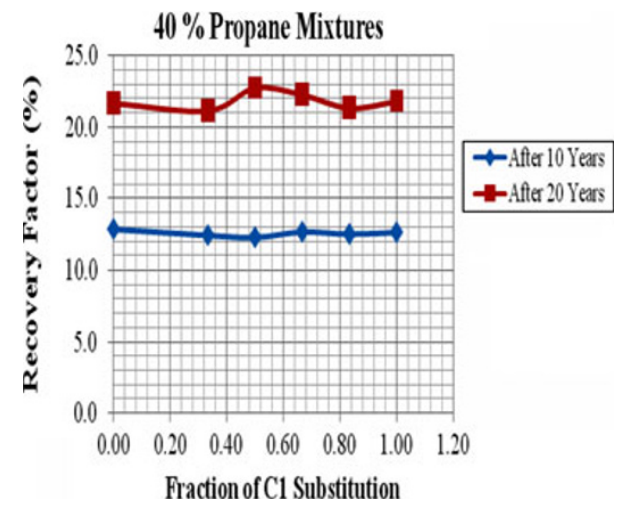

Fig. 13 Recovery versus $\mathrm{CO}_{2} \%$ in $\mathrm{C}_{1}-\mathrm{C}_{3}-\mathrm{CO}_{2}$ mixture

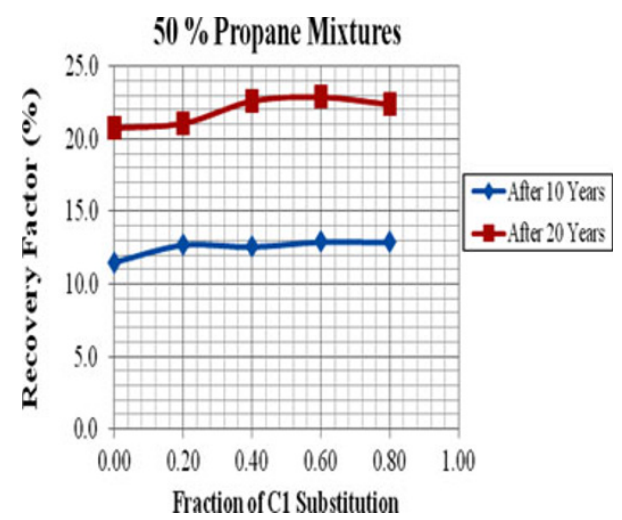

Fig. 14 Recovery versus $\mathrm{CO}_{2} \%$ in $\mathrm{C}_{1}-\mathrm{C}_{3}-\mathrm{CO}_{2}$ mixture

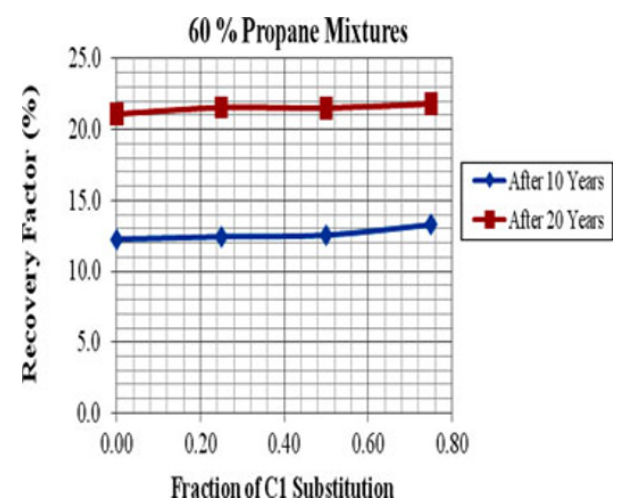

Fig. 15 Recovery versus $\mathrm{CO}_{2} \%$ in $\mathrm{C}_{1}-\mathrm{C}_{3}-\mathrm{CO}_{2}$ mixture

substituted by the $\mathrm{CO}_{2}$ gas in the injected solvent for $\mathrm{CO}_{2}$-based VAPEX should generally not exceed $50 \%$. This finding helps in the design of $\mathrm{CO}_{2}$-based VAPEX processes for future large-scale laboratory and pilot investigations.

\section{Effect of reservoir temperature}

The base case simulation was run with a constant reservoir temperature of $22{ }^{\circ} \mathrm{C}$. To cover a wider range of 
Table 3 Increase in recovery factor for various temperature increments

\begin{tabular}{|c|c|c|c|c|c|c|c|c|}
\hline \multirow{2}{*}{\multicolumn{3}{|c|}{ Solvent Composition }} & \multicolumn{6}{|c|}{ Increase In Recovery Factor (\%) } \\
\hline & & & \multicolumn{2}{|c|}{$17-22^{\circ} \mathrm{C}$} & \multicolumn{2}{|c|}{$22-27^{\circ} \mathrm{C}$} & \multicolumn{2}{|c|}{$17-27^{\circ} \mathrm{C}$} \\
\hline $\mathrm{C}_{1}(\mathrm{~mol} \%)$ & $\mathrm{C}_{3}(\mathrm{~mol} \%)$ & $\mathrm{CO}_{2}(\mathrm{~mol} \%)$ & $10 \mathrm{yr}$ & $20 \mathrm{yr}$ & $10 \mathrm{yr}$ & $20 \mathrm{yr}$ & $10 \mathrm{yr}$ & $20 \mathrm{yr}$ \\
\hline 20 & 40 & 40 & 4.3 & 6.1 & 5.1 & 8.4 & 9.5 & 14.5 \\
\hline 30 & 40 & 30 & 4.0 & 6.5 & 5.7 & 7.6 & 9.6 & 14.1 \\
\hline 30 & 50 & 20 & 3.9 & 6.7 & 4.8 & 6.2 & 8.7 & 12.9 \\
\hline 40 & 40 & 20 & 4.2 & 5.3 & 5.7 & 10.6 & 9.9 & 15.9 \\
\hline 40 & 50 & 10 & 4.0 & 5.4 & 4.6 & 7.6 & 8.6 & 12.9 \\
\hline 33 & 33 & 34 & 4.3 & 7.4 & 3.3 & 5.1 & 7.7 & 12.5 \\
\hline 20 & 20 & 60 & 2.4 & 3.5 & 2.7 & 3.8 & 5.2 & 7.2 \\
\hline 10 & 10 & 80 & 2.0 & 3.0 & 2.3 & 3.1 & 4.3 & 6.1 \\
\hline 30 & 30 & 40 & 3.7 & 6.0 & 2.5 & 3.6 & 6.2 & 9.6 \\
\hline 20 & 30 & 50 & 3.5 & 5.6 & 3.1 & 4.8 & 6.6 & 10.4 \\
\hline 30 & 20 & 50 & 2.6 & 3.6 & 2.6 & 3.5 & 5.1 & 7.1 \\
\hline 50 & 30 & 20 & 3.2 & 4.6 & 2.9 & 4.2 & 6.1 & 8.8 \\
\hline 10 & 20 & 70 & 2.4 & 3.3 & 2.8 & 4.2 & 5.2 & 7.5 \\
\hline 40 & 30 & 30 & 3.3 & 4.8 & 2.7 & 4.1 & 6.0 & 9.0 \\
\hline 60 & 30 & 10 & 2.5 & 3.1 & 2.9 & 4.3 & 5.4 & 7.4 \\
\hline 70 & 20 & 10 & 2.2 & 3.0 & 2.5 & 3.3 & 4.7 & 6.3 \\
\hline 60 & 20 & 20 & 2.2 & 3.2 & 2.6 & 3.4 & 4.8 & 6.7 \\
\hline 50 & 20 & 30 & 2.4 & 3.5 & 2.5 & 3.4 & 4.9 & 6.8 \\
\hline 40 & 20 & 40 & 2.5 & 3.4 & 2.6 & 3.6 & 5.0 & 7.1 \\
\hline Average & & & 3.1 & 4.6 & 3.4 & 5.0 & 6.5 & 9.6 \\
\hline
\end{tabular}

temperatures that may be encountered in Canadian heavyoil reservoirs, several simulation runs were performed at two alternate temperatures. One temperature on either side of the base case temperature was chosen: 17 and $27^{\circ} \mathrm{C}$. An increase in temperature led to a significant increase in oil-recovery factor. Table 3 summarizes the increase in oil-recovery factor for each solvent over the range of temperatures used in the simulations. Only solvents that were primarily vapour were compared. This limited the number of solvents that can be used at the lowest temperature. On average, a temperature increase of $5{ }^{\circ} \mathrm{C}$ generates a 3-5\% increase in oil-recovery factor. Figure 16 shows the cumulative production versus time for the same injected solvent (composition: $60 \% \mathrm{C}_{1}+40 \% \mathrm{C}_{3}$ ) at 22 and $27{ }^{\circ} \mathrm{C}$. The cumulative oil production during the time was steadily higher for the higher temperature of $27^{\circ} \mathrm{C}$.

\section{Effect of reservoir pressure}

The pressure differential between the injection and production wells was maintained at $50 \mathrm{kPa}$ for both reservoir pressures used in the simulations. Four different solvents were compared, each containing a different fraction of $\mathrm{CO}_{2}$. The propane content of each solvent was $20 \%$ (see Fig. 17). Figure 17 is related to the recovery factor after

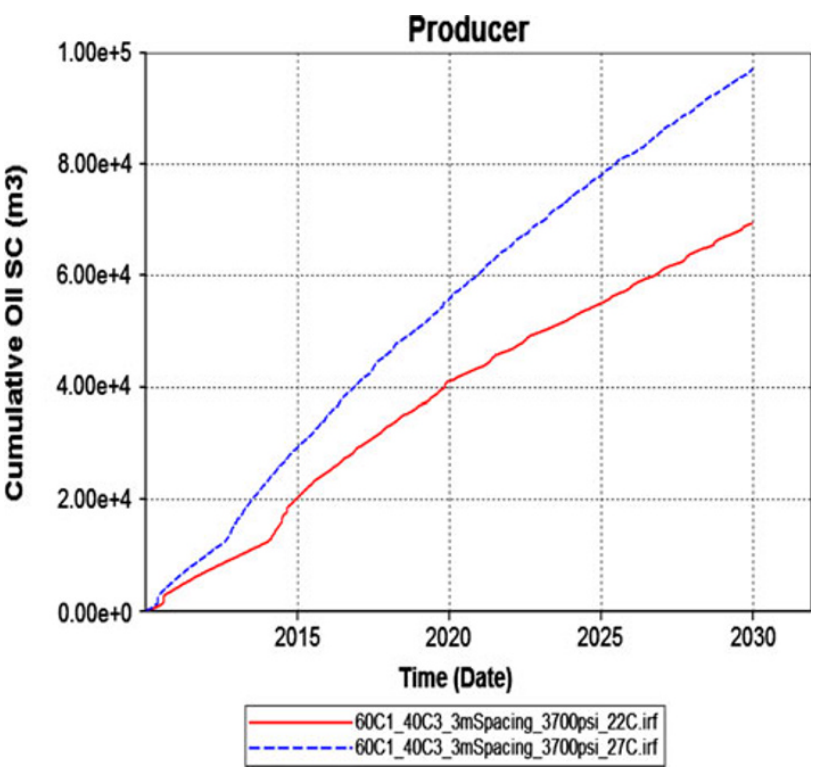

Fig. 16 Cumulative oil production at 22 and $27^{\circ} \mathrm{C}$

20 years of solvent injection at both reservoir pressures of 3,700 and $5,700 \mathrm{kPa}$. The oil-recovery factor at a given pressure was improved as the fraction of $\mathrm{CO}_{2}$ in the solvent increased. In addition, the overall oil-recovery factor for a given solvent was greater at the higher reservoir pressure. 


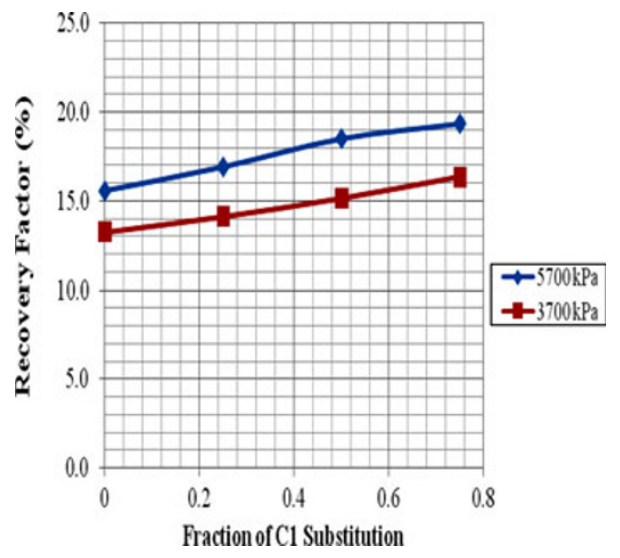

Fig. 17 Effect of pressure on recovery $\left(20 \% \mathrm{C}_{3}\right)$

The increase in oil-recovery factor was noticeably greater for solvents containing $\mathrm{CO}_{2}$ than for the solvent containing only methane and propane. This is attributed to the fact that the solubility of $\mathrm{CO}_{2}$ in heavy oil increases with pressure. At increased pressures, the amount of non-condensable gas (i.e., $\mathrm{CO}_{2}$ ) required to maintain a vapour phase increases. The increasing $\mathrm{CO}_{2}$ content resulted in considerably higher exposure of the $\mathrm{CO}_{2}$ to the oil (i.e., increase in interfacial contact between the $\mathrm{CO}_{2}$ and the heavy oil). Therefore, the increase in solubility of the $\mathrm{CO}_{2}$ into the oil is the consequence of such an increased exposure. A negative sideeffect of this phenomenon is a decrease in the solubility of the propane that is present in the solvent. The increase in the $\mathrm{CO}_{2}$ solubility generally outweighs the reduced propane solubility, and therefore, the incorporation of $\mathrm{CO}_{2}$ into the solvent becomes more beneficial at higher pressures.

\section{Effect of vertical well spacing}

The vertical distance between the injection and the production wells was kept constant at $3 \mathrm{~m}$ for the previous simulation runs. The optimal well spacing to be used varies with the type of oil in the reservoir. Several well spacings were considered for the simulation runs, ranging from 3 to $8 \mathrm{~m}$. This particular simulation was different from the previous simulation runs, in that, only solvents containing all three components, methane, propane and $\mathrm{CO}_{2}$, were tested. Two types of solvents were chosen based on their performance throughout previous runs: (1) solvent 1 with a composition of $20 \% \mathrm{C}_{1}+20 \% \mathrm{C}_{2}+60 \% \mathrm{CO}_{2}$ and (2) solvent 2 with a composition of $33 \% \quad \mathrm{C}_{1}+33 \% \quad \mathrm{C}_{2}+34 \% \quad \mathrm{CO}_{2}$. According to Fig. 18, for oil $\mathrm{A}$ and with the given reservoir characteristics, the optimal vertical spacing between the wells was $6-7 \mathrm{~m}$. This relatively wide spacing is possible since the oil is not very viscous (with viscosities in the order of $10^{3}-10^{4} \mathrm{mPa}$ s, as shown in Table 2), as compared to some heavy oils with viscosities in the order of $10^{5} \mathrm{mPa} \mathrm{s}$.

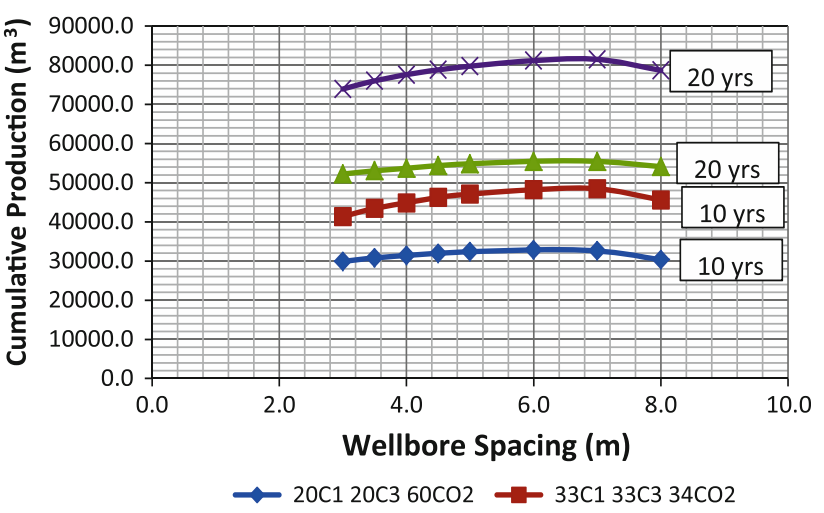

Fig. 18 Cumulative oil production versus well spacing for two different solvents: (1) solvent 1 with a composition of $20 \%$ $\mathrm{C}_{1}+20 \% \mathrm{C}_{2}+60 \% \mathrm{CO}_{2}$ and (2) solvent 2 with a composition of $33 \% \mathrm{C}_{1}+33 \% \mathrm{C}_{2}+34 \% \mathrm{CO}_{2}$

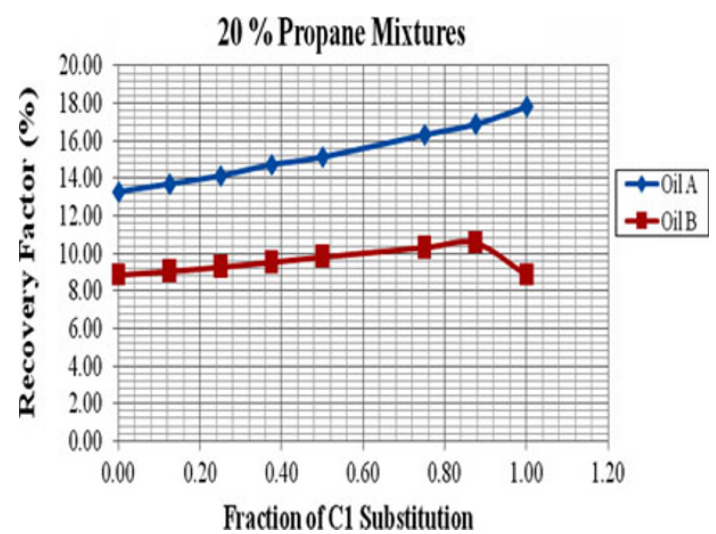

Fig. 19 Effect of oil type on recovery $\left(20 \% \mathrm{C}_{3}\right.$ in solvent $)$

Effect of oil composition

It is necessary to test the applicability of a $\mathrm{CO}_{2}$-based VAPEX to oil with higher viscosity than oil A. The viscosity of oil B at different temperatures is given in Table 2. The reservoir conditions and all other simulation parameters were equal to those of the base case. Figure 19 shows the comparison of oil A and oil B in terms of their performance with solvents containing $20 \%$ propane. As expected, the oil-recovery factors in the runs using oil B are substantially lower. As with oil A, the substitution of $\mathrm{CO}_{2}$ in the solvent generated equally good or better oilrecovery factors than the solvents containing only methane and propane. Figure 20 shows the effect of adding $\mathrm{CO}_{2}$ to solvents injected into a reservoir containing oil B after 10 and 20 years. The oil-recovery factor for oil B after both 10 and 20 years decreased noticeably when the injected solvent contained the maximum fraction of the $\mathrm{CO}_{2}$ gas (i.e., when the fraction of $\mathrm{C}_{1}$ substitution becomes 1.0). In fact, the oil recovery for oil $\mathrm{B}$ was enhanced by adding $\mathrm{CO}_{2}$ to the injected solvent within the

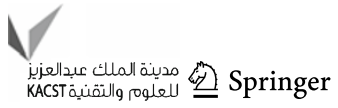




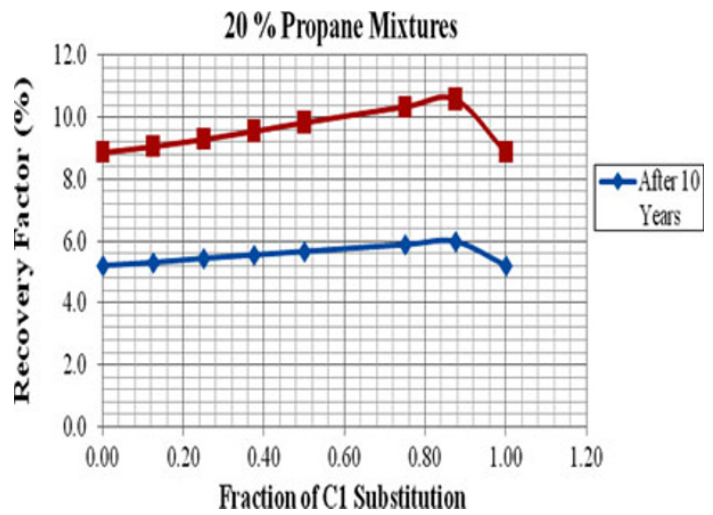

Fig. 20 Recovery for oil $B\left(20 \% \mathrm{C}_{3}\right.$ in solvent)

range of $0-0.80$ fraction of $\mathrm{C}_{1}$ substitution. The oil recovery for oil $\mathrm{B}$ reached its minimum when the fraction of $\mathrm{C}_{1}$ substitution becomes 1.0. This behavior was not observed for oil A.

To sum up, this work was an attempt to solely focus on the effect of modifying oil/solvent composition under different pressures and temperatures. As it was mentioned in the "Introduction", one of the motivations for adding $\mathrm{CO}_{2}$ to propane as solvent in VAPEX is to sequester $\mathrm{CO}_{2}$ in the reservoir. The discussion on the amount of $\mathrm{CO}_{2}$ trapped in the formation is a subject that falls beyond the scope of this paper. The same discussion holds for examining the effect of high water saturation on $\mathrm{CO}_{2}$ VAPEX, which is a completely different topic. These factors can be the subjects of future investigations. In addition, unlike in SAGD, the presence of shale does not seem to have a noticeable effect on the $\mathrm{CO}_{2}$ VAPEX as shale (swelling) is not susceptible to the presence of $\mathrm{CO}_{2}$.

\section{Summary and conclusions}

1. The incorporation of $\mathrm{CO}_{2}$ into the solvent for a VAPEX process appears to be a viable option. Replacing a portion of the methane in the solvent with $\mathrm{CO}_{2}$ resulted in equal or greater recovery factors in the majority of the simulations conducted. If reservoir conditions permit, the non-condensable gas portion of the solvent should be less than $60 \%$ of the total mixture. Adding $\mathrm{CO}_{2}$ to the solvent is more beneficial at higher reservoir pressures. The performance of the solvents containing $\mathrm{CO}_{2}$ was greater at a reservoir pressure of $5,700 \mathrm{kPa}$ than at $3,700 \mathrm{kPa}$.

2. Reservoir temperature significantly impacts the performance of the VAPEX process. A temperature increase of only $5{ }^{\circ} \mathrm{C}$ led to an increase in oil recovery factor of over $3 \%$ on average. Solubility of the solvent in the oil and the vapour fraction in the solvent are greater at higher temperatures. Therefore, higher initial reservoir temperature is beneficial for a VAPEX project. This result also indicates that warm VAPEX or hybrid VAPEX processes can provide better results than the conventional VAPEX.

3 . The greatest oil-recovery factors were achieved with a vertical distance between the production and injection wells of 6-7 m. This relatively large spacing was made possible by the homogenous properties of the reservoir and the moderate viscosity of the oil used in the simulation. The optimal spacing will be different for every reservoir and must be small enough that communication between the two wells can be established within a reasonable period of time.

4. The initial viscosity of the oil in the reservoir must be taken into consideration before implementing a VAPEX project. The effectiveness of the process was significantly reduced when a heavier and more viscous oil was used in the simulation. Nevertheless, the addition of $\mathrm{CO}_{2}$ into the solvent proved to be feasible for the more viscous oil as well. Recovery factors using solvents containing $\mathrm{CO}_{2}$ were equal to or greater than those obtained using methanepropane mixtures.

Open Access This article is distributed under the terms of the Creative Commons Attribution License which permits any use, distribution, and reproduction in any medium, provided the original author(s) and the source are credited.

\section{References}

Badamchi-Zadeh A, Maini BB, Yarranton HW (2008) Applicability of $\mathrm{CO}_{2}$-based Vapex process to recover Athabasca bitumen. In: SPE/PS/CHOA international thermal operations and heavy oil symposium, Calgary, Alberta, Canada

Badamchi-Zadeh A, Yarranton HW, Maini BB, Satyro MA (2009) Phase behaviour and physical property measurements for VAPEX solvents: part II. propane, carbon dioxide and Athabasca bitumen. J Can Petrol Tech 48(3):57-65

Butler RM (1991) Thermal recovery of oil and bitumen. PrenticeHall, New Jersey

Butler RM, Mokrys IJ (1991) A new process (VAPEX) for recovering heavy oils using hot water and hydrocarbon vapour. J Can Petrol Tech 30(1):97-105

Butler RM, Mokrys IJ, Das SK (1995) The solvent requirements for Vapex recovery. In: SPE international heavy oil symposium. Calgary, Alberta, Canada

Das SK, Butler RM (1998) Mechanism of the vapor extraction process for heavy oil and bitumen. J Pet Sci Eng 21(1-2):43-59

Farouq Ali SM (1974) Heavy oil recovery: principles, practicality, potential and problems. In: SPE rocky mountain regional meeting, Billings, Montana, USA

Farouq Ali SM (1976) Non-thermal heavy oil recovery methods. In: SPE rocky mountain regional meeting, Casper, Wyoming, USA

James LA, Rezaei N, Chatzis I (2007) VAPEX, warm VAPEX and hybrid VAPEX: the state of enhanced oil recovery for in situ heavy oils in Canada. J Can Petrol Tech 47(4):12-18 
Liu Q, Dong M, Ma S (2006) Alkaline/surfactant flood potential in Western Canadian heavy oil reservoirs. In: SPE/DOE symposium on improved oil recovery, Tulsa, Oklahoma, USA

Luhning RW, Das SK, Fisher LJ, Bakker J, Grabowski J, Engleman JR, Wong S, Sullivan LA, Boyle HA (2003) Full-scale VAPEX process-climate change advantage and economic consequences. A J Can Petrol Tech 42(2):29-33

Luo P, Gu Y (2005) Effects of asphaltene content and solvent concentration on heavy-oil viscosity. In: SPE/PS-CIM/CHOA international thermal operations and heavy oil symposium, Calgary, Alberta, Canada

Luo P, Yang C, Tharanivasan AK, Gu Y (2007) In situ upgrading of heavy oil in a solvent-based heavy oil recovery process. J Can Petrol Tech 46(9):37-43

Mai A, Kantzas A (2010) Mechanisms of heavy oil recovery by low rate waterflooding. J Can Petrol Tech 49(3):44-50

Mai A, Bryan J, Goodarzi N, Kantzas A (2009) Insights into nonthermal recovery of heavy oil. J Can Petrol Tech 48(3):27-35

Rojas GA, Zhu T, Dyer SB, Thomas S, Farouq Ali SM (1991) Scaled model studies of $\mathrm{CO}_{2}$ floods. SPE Reservoir Eng 6(2):169-178

Spivak A, Chima CM (1984) Mechanisms of immiscible $\mathrm{CO}_{2}$ injection in heavy oil reservoirs, Wilmington Field, CA. In: SPE enhanced oil recovery symposium, Tulsa, Oklahoma, USA

Talbi K, Maini BB (2004) Further investigation of $\mathrm{CO}_{2}$ based Vapex for the recovery of heavy oils and bitumen. In: Canadian international petroleum conference, Calgary, Alberta, Canada

Thomas S, Farouq Ali SM, Scoular JR, Verkoczy B (2001) Chemical methods for heavy oil recovery. J Can Petrol Tech 40(3):56-61
Torabi F, Jamaloei BY, Zarivnyy O, Paquin B, Rumpel N (2012) The evaluation of variable-injection rate waterflooding, immiscible $\mathrm{CO}_{2}$ flooding, and water-alternating- $\mathrm{CO}_{2}$ injection for heavy oil recovery. Petrol Sci Tech 30(16):1-14

Turta AT, Singhal AK (2004) Overview of short-distance oil displacement processes. J Can Petrol Tech 43(2):29-38

Turta TA, Singhal AK, Xia TX, Greaves M, Goldman J, Ivory J (2008) Preliminary consideration on application of steamflooding in a toe-to-heel configuration. In: Proceedings of the Canadian international petroleum conference/SPE gas technology symposium joint conference, Calgary, Alberta, Canada

Upreti SR, Lohi A, Kapadia RA, El-Haj R (2007) Vapor extraction of heavy oil and bitumen: a review. Energy Fuels 21(3):1562-1574

Xia TX, Greaves M, Turta AT, Ayasse C (2003) THAI- a 'shortdistance displacement' in situ combustion process for the recovery and upgrading of heavy oil. Chem Eng Res Des 81(3):295-304

Yadali Jamaloei B, Kharrat R (2010) Analysis of microscopic displacement mechanisms of dilute surfactant flooding in oil-wet and water-wet porous media. Transp Porous Media 81(1):1-19

Yadali Jamaloei B, Asghari K, Kharrat R, Ahmadloo F (2010a) Porescale two-phase filtration in imbibition process through porous media at high- and low-interfacial tension flow conditions. J Petrol Sci Eng 72(3-4):251-269

Yadali Jamaloei B, Kharrat R, Torabi F (2010b) Analysis and correlations of viscous fingering in low-tension polymer flooding in heavy oil reservoirs. Energy Fuels 24(12):6384-6392 